\title{
Review on Partial Discharge and Time Domain Reflectometry using Finite Element Analysis
}

\author{
Nur Haziqah Syazni Mohd Hatta ${ }^{1}$, Tze Mei Kuan ${ }^{2}$, Azrul Mohd Ariffin ${ }^{3}$, Wong Jee Keen Raymond ${ }^{4}$ \\ ${ }^{1,2,3}$ Universiti Tenaga Nasional, Malaysia, \\ ${ }^{4}$ Tunku Abdul Rahman University College, Malaysia \\ 1'haziqahsyazni97@ gmail.com, ${ }^{2}$ tzemei@ uniten.edu.my, ${ }^{3}$ azrula@ uniten.edu.my, ${ }^{4}$ wongjk@ tarc.edu.my
}

\begin{abstract}
In this paper, the concept of Partial Discharge (PD) and Time Domain Reflectometry (TDR) are discussed as they are among the most commonly used technique by utility company to enhance the fault characterization during routine based maintenance or failure in the system. The aim of this paper to review a technique that is able to shorten the period of cable fault diagnosis so that the replacement of cable can take place more efficiently. Correspondingly, this paper will investigate the ability of combining both techniques (PD and TDR) to reduce the cable replacement cost and subsequently prolong the lifespan of the cable. The proposed technique combination of PD, water tree and TDR with finite element analysis has been discussed in this paper. It can be seen, for future development the technique combination could be improve to monitor the cable health efficiently.
\end{abstract}

Key words : fault detection, finite element analysis, partial discharge, time domain reflectometry

\section{INTRODUCTION}

Partial discharge (PD) technique is one of the popular techniques used to detect fault on power line cable. Usually PD is used in routine based maintenance to detect and monitor the health condition of cable [1]-[4]. Regular maintenance can increase the lifespan of the cable and reduce the breakdown possibilities of older cable to prevent any interruption of customer's electricity. Thus, the restoration of cable can be done efficiently.

PD happens due to voids or cavities in solid and liquid medium of insulation. Studies in [3], [5], [6] have shown improper installation by poor design or workmanship and also over stressing of thermal and electrical. The voids occurs produce $\mathrm{PD}$ take place between insulation and conductor or insulation at outer semi conductive screen [7], [8]. Based on experiment from study in [7], void in cable can happen on two conditions such as inception field, Einc is much smaller compared to the field magnitude in the center of void and the presence of free electron. Usually, PD does detect the type of fault along the cable but not the exact location of the fault [9]-[13]. Most of the studies are focusing on locating fault without the presence of cable ducts. In real situation of on-site, cable is installed with ducts especially metal ducts which will affect the fault pinpointing activities.

Meanwhile, time domain reflectometry (TDR) is a difference of signal time between the arrival of pulse and its reflection at the far end of the cable [14]-[17]. It will measure the total length of the cable, the location of low resistance cable faults, the location of cable interruptions and the point of joints along the cable by injecting low voltage of pulse on the cable at any impedance and wait until the reflections seen [16]. The distance of reflections is according to total time and propagation velocity of pulse which determined the type of impedance change and failure in the cable [14]. This technique will benefit the utilities company by reducing the period of fault pinpointing and allows the cable replacement efficiently.

Based on [18], fault identification are not just affected by time, deficiency resistance, issue type, fault line area and ground improvement but suggested issue identifier need to discover through the shortcoming of those broken period. Thus, development of system can be build based on the certain issue.

Therefore, this paper aims to study the capability of combining PD, TDR and water tree in fault pinpointing on cable, using the finite-element analysis technique so that the fault can be identified immediately. Thus, in future more development of this technique can be improved to shorten the period of cable replacement and reduce the cost of major breakdown through early detection that gives direct impact on reducing the electricity disruption possibility and at the same time increase the lifetime of cable.

\section{LITERATURE REVIEW}

As the time goes by, the energy consumers are increasing rapidly especially for electrical energy. The instability is cause due to heavy load demand where the limit of operation are close. Thus, reliable stability is important to avoid the increasing transmission or energy loss in a power system. It 
Nur Haziqah Syazni Mohd Hatta et al., International Journal of Emerging Trends in Engineering Research, 8(1.1), 2020, $179-186$

is important to have a strong strategy and adopt optimal to utilize the efficiency [19], [20].

This raises awareness of the importance of electrical energy in people's lives to engage and use technology that becomes a necessity for life. Unfortunately, as the consumers increases, the services from power utility company also must be improved to cater all the customers demand. Consequently, the combination of technique PD-TDR is introduced to reduce any power outage and at the same time, stronger the power utility company reputation.

PD technique is divided into two parts: online and offline. Offline PD are standardized in IEC 60270. The normal operation system needs to de-energized and energized by external voltage source to test the equipment. Meanwhile, online method will demonstrate the exact behavior to evaluate at the normal operating voltage [21]. Based on [22], most of PD are equipped with time domain reflection analysis which allow users to detect the location of fault from the source.

Study in [23] shows, PD can developed and simulated using finite element analysis using COMSOL to observe the difference characteristics and behavior of PD discharges in insulation medium of electric cable. Three different shapes of voids used in the experiment with different types of insulation. This method will discussed later in another section.

Meanwhile, the advantages of TDR compared to other methods in enhancing the fault detection is because it provides series measurements in intensive time. Since 1980s when it first introduced, based on different principles it has increase stimulated interest [14]. Moreover, with the continuous improvement of technology make the cost of TDR operation is inexpensive. At the same time, TDR method is maturing thus, many useful ranges of applications that derived directly from TDR method.

Furthermore, study in [24] shows the water tree effect in cable was analyzed using finite-element method using two different types of cable. Thus, the idea of combination can be made of using finite-element analysis with TDR in [2], to detect the presence of water tree which also will be discussed in another section later.

Besides, finite element method is commonly used in modelling engineering phenomenon [7]. It is an effective tool to characterize and perform good reliability and accuracy which can modelled different behavior of cables such as mechanical, thermal, electromagnetic and coupled analyses. At the same time, finite element method can analyze the presence of defect in insulation layer at different level of electric field strength even though the maximum values is higher than the values declared [25].

\section{METHODOLOGY}

Since the purpose of this paper is to investigate the technique of PD and TDR in finite element structure analysis, two different methods of application will be modelled and compared in this paper. COMSOL Multiphysics software is used based on studies in [23], [26]. Other than COMSOL Multiphysics, MATLAB Simulink are also used in determining cable fault as seen in [23] as it is competence in translating the language of COMSOL and at the same time, make it simple for user to plot data or functions, implement algorithms and build graphical user interface. The model of PD in COMSOL are drawn as:

1. 2D shapes to solve transient and time-harmonic analysis

2. Then, void are divided into five channels to add any unpredictable actions of the PD operation

3. $0.1 \mathrm{~mm}$ thick of layers was added in the model of cavity surface

4. Different shapes of void used such as cylindrical, spherical and unsymmetrical

5. Sinusoidal waveform will produce by applying electric potential varied by the time $(\mathrm{t})$ to replicate behavior of an AC signal with $10 \mathrm{kV}$ amplitude.

The example of void in cable are drawn in COMSOL as in Figure 1.

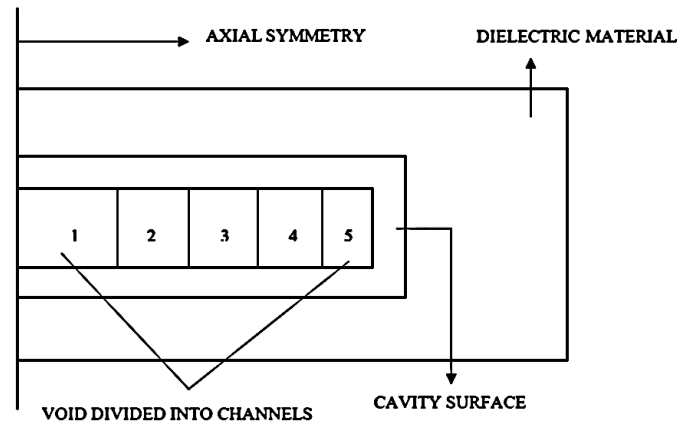

Figure 1: PD drawn in COMSOL [23]

There are three types of insulating material used such as polycarbonate, silicone rubber and silicon carbide and observed at three different location of insulation: center, near ground electrode and near high voltage electrode. The shape of void also tested differently for cylindrical, spherical and unsymmetrical. Since the mesh is less, the duration of insulation also reduced.

For TDR, the idea of TDR circuit as Figure 2 below. The TDR will send low voltage of impulse signal through cable and checks for any reflections due to the impedance mismatch. If there is any discontinuity, some part of pulsed signal reflected will send back to TDR. In addition, TDR can detect exact location of fault of open circuit, short circuit and impedance mismatch. 


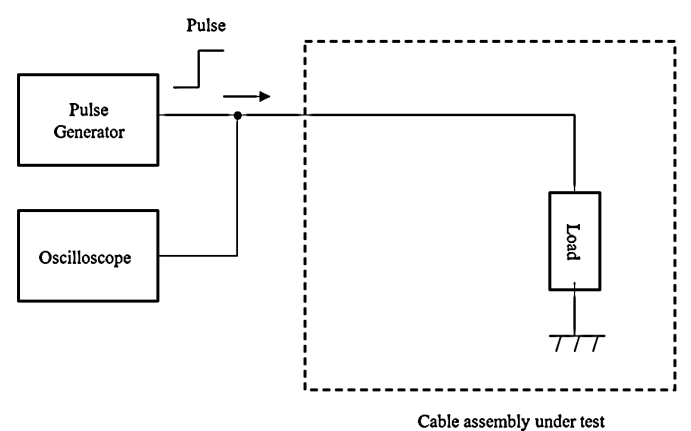

Figure 2: TDR block diagram

To detect the location of fault in the cable, it can be measured by time and propagation of velocity of the received pulse. It can be determined from

$D=V_{p}\left(\frac{T}{2}\right)$

where $v$ is distance in meter, $V_{p}$ is the velocity of propagation in $\mathrm{m} / \mathrm{s}$ and ${ }^{T}$ is transit time from the monitoring point to the mismatch in seconds. Based on [2], TDR technique will use finite element analysis simulated by COMSOL Multiphysics. This is because, PD technique are not able to detect water trees because PD produces electrical tree. Thus, TDR method will help to detect the present of water tree at the same it will detect the location of the fault.

From [24], to detect water tree present in a cable, two types of cable used in the experiment. The details of two cables are shown in table below.

Table 1: Types of cable used

\begin{tabular}{|c|c|}
\hline Tape shield cable & $\begin{array}{c}\text { Concentric neutral } \\
\text { cable }\end{array}$ \\
\hline 750 kcmil & $1 / 0$ AWG \\
\hline XLPE insulation & XLPE insulation \\
\hline Copper tape shield & $\begin{array}{c}\text { Six copper concentric } \\
\text { neutral wires }\end{array}$ \\
\hline $\begin{array}{c}\text { Stranded aluminum } \\
\text { conductor }\end{array}$ & $\begin{array}{c}\text { Stranded aluminum } \\
\text { conductor }\end{array}$ \\
\hline
\end{tabular}

In COMSOL, the water tree modelled through Magnetic and Electric Fields physics branch and Electric Circuit physics branch. To obtain proper calculation of magnetic and electric field, the cable surrounds by air medium. Thus, magnetic field are allowed to pass outside of the cable. Then, to place a voltage between the conductor and shield or neutral wires, the cable terminals are attached to the circuit so the current can be fed into the cable. Next, the electric field of water tree can be observed when the electric field flow through the installation. At the same time, the amplification of the electric field can be seen at the water tree's trip. Figure 3 shows the model of two cables in COMSOL.
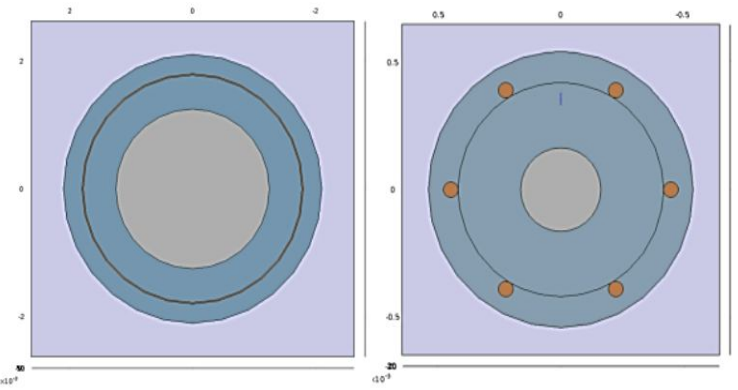

Figure 3: Tape shield cable and concentric neutral cable [24]

\section{RESULTS AND DISCUSSIONS}

Based on the result of simulation in [23], the lowest value of the distribution of electric field are unsymmetrical shaped of void as compared in table $3-5$. This is because, unsymmetrical void shapes are highly prone to damage that the definite shaped of void. This can be shown from the results in figure 4 -6 of unsymmetrical shape of field distribution used for cavity-voltage analysis from different types of solid dielectric below :
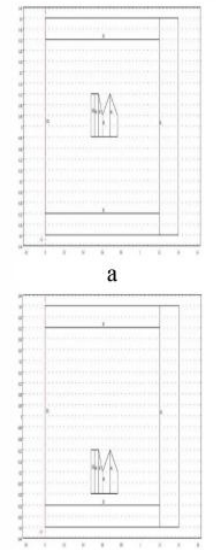

b

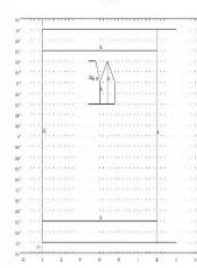

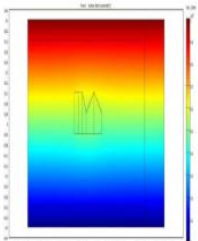
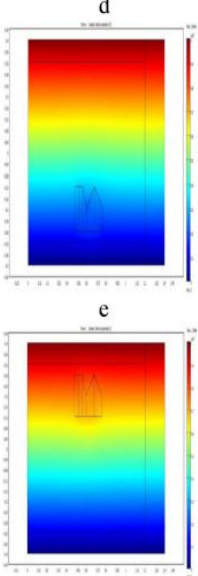

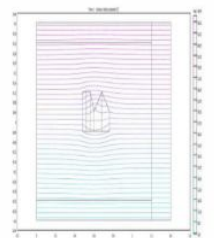

g

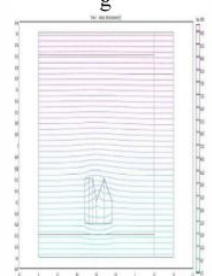

$\mathrm{h}$

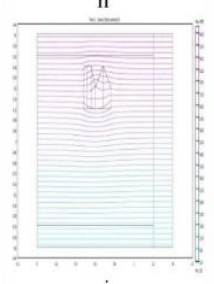

Figure 4: Model of PD for unsymmetrical void at polycarbonate insulation. (a-c) Model of PD activity within the unsymmetrical cavity at the centre of insulation, close to ground and close to high voltage electrode (d-i) Surface \& contour plots of field distribution for unsymmetrical cavity at the centre of insulation, close to ground and close to high voltage electrode. [23] 


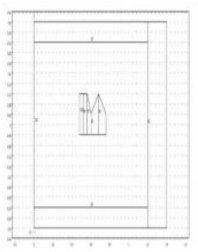

a
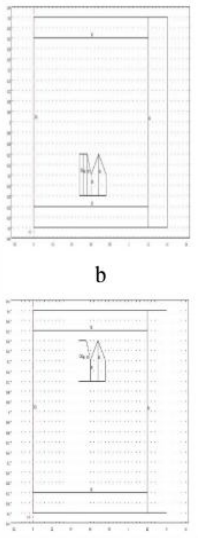

$\mathrm{c}$

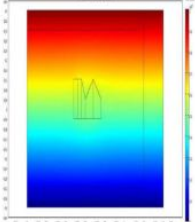

d

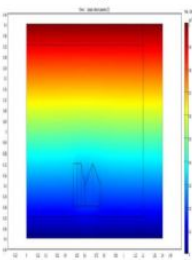

e

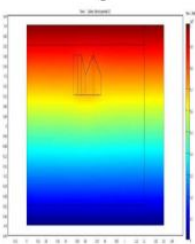

$f$
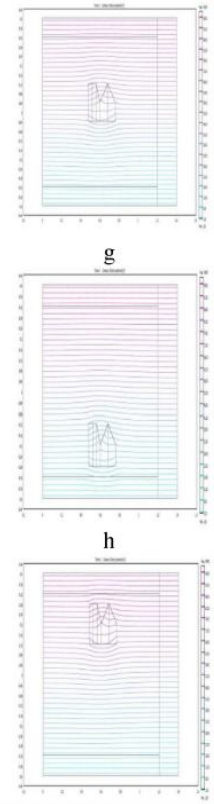

i
Figure 5: Model of PD for unsymmetrical void at silicone rubber insulation (a-c) Model of PD activity within the unsymmetrical cavity at the centre of insulation, close to ground and close to high voltage electrode (d-i) Surface \& contour plots of field distribution for unsymmetrical cavity at the centre of insulation, close to ground and close to high voltage electrode [23]
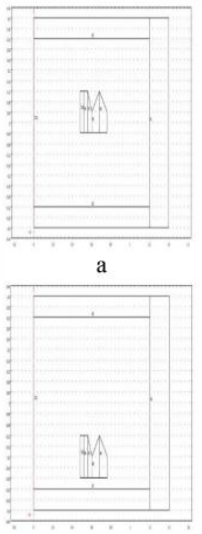

b

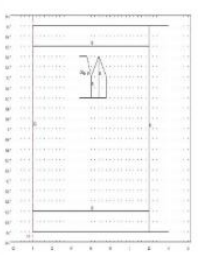

c
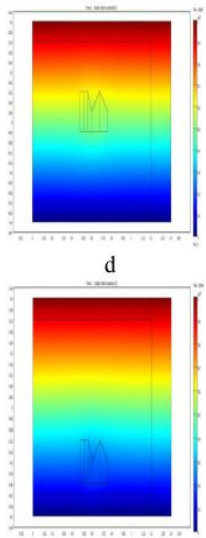

e

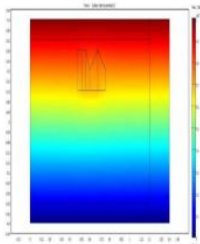

$\mathrm{f}$
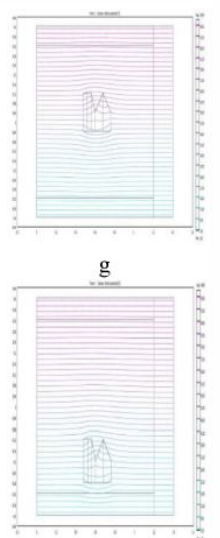

$\mathrm{h}$

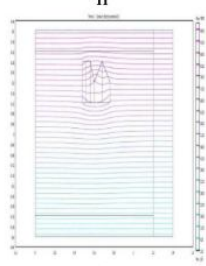

i
Figure 6: Model of PD for unsymmetrical void at silicon carbide insulation (a-c) Model of PD activity within the unsymmetrical cavity at the center of insulation, close to ground and close to high voltage electrode

(d-i) Surface \& contour plots of field distribution for unsymmetrical cavity at the center of insulation, close to ground and close to high voltage electrode [23]
The least of possibility for insulation breakdown are observed and shown in

Table 2 when applied voltage of $10 \mathrm{kV}$ is used as reference for voltage generated cavity.

Table 2: Least of possibility for insulation cable breakdown happened [23]

\begin{tabular}{|c|l|l|l|c|}
\hline \multirow{2}{*}{$\begin{array}{c}\text { Insulating } \\
\text { material }\end{array}$} & $\begin{array}{c}\text { Shape } \\
\text { of void }\end{array}$ & $\begin{array}{c}\text { Centre of } \\
\text { Insulation }\end{array}$ & $\begin{array}{c}\text { Near } \\
\text { ground } \\
\text { electrode }\end{array}$ & $\begin{array}{c}\text { Near } \\
\text { high } \\
\text { voltage } \\
\text { electrode }\end{array}$ \\
\hline \multirow{2}{*}{ Polycarbonate } & Sphere & & $/$ & \\
\cline { 2 - 5 } & Cylindrical & $/$ & & $/$ \\
\hline $\begin{array}{c}\text { Silicone } \\
\text { Rubber }\end{array}$ & Sphere & & $/$ & \\
\cline { 2 - 5 } & Cylindrical & $/$ & & $/$ \\
\hline \multirow{2}{*}{$\begin{array}{c}\text { Silicon } \\
\text { Carbide }\end{array}$} & Sphere & & $/$ & \\
\cline { 2 - 5 } & Cylindrical & $/$ & & $/$ \\
\hline
\end{tabular}

Below is the comparisons of the distribution of electrical field for all insulation models from [23].

Table 3: Electric field distribution of void in polycarbonate insulation [23]

\begin{tabular}{|c|c|c|c|c|c|c|}
\hline \multirow{2}{*}{$\begin{array}{c}\text { Shape of } \\
\text { cavity }\end{array}$} & \multirow{2}{*}{$\begin{array}{c}\text { Positi } \\
\text { on of } \\
\text { cavity }\end{array}$} & \multicolumn{5}{|c|}{ Electric field in channels (V) } \\
\hline & & 1 & 2 & 3 & 4 & 5 \\
\hline \multirow{6}{*}{$\begin{array}{c}\text { Cylindric } \\
\text { al }\end{array}$} & Groun & 3154 & 3294 & 3105 & 3197 & 3212 \\
\hline & $\begin{array}{c}\mathrm{d} \\
\text { Electr } \\
\text { ode }\end{array}$ & .11 & .44 & .73 & .11 & .53 \\
\hline & Center & 4861 & 4995 & 4564 & 4779 & 4794 \\
\hline & $\begin{array}{c}\text { of } \\
\text { insulat } \\
\text { ion }\end{array}$ & .30 & .98 & .28 & .26 & \\
\hline & High & 6960 & 7045 & 6892 & 6893 & 6892 \\
\hline & $\begin{array}{c}\text { voltag } \\
\text { e } \\
\text { electr } \\
\text { ode }\end{array}$ & .70 & .59 & .60 & .06 & .96 \\
\hline \multirow[t]{6}{*}{ Spherical } & Groun & 3610 & 3659 & 3575 & 3585 & 3603 \\
\hline & $\begin{array}{c}\mathrm{d} \\
\text { Electr } \\
\text { ode }\end{array}$ & .02 & .02 & .82 & .9 & .04 \\
\hline & Center & 5202 & 5203 & 5123 & 5125 & 5127 \\
\hline & $\begin{array}{c}\text { of } \\
\text { insulat } \\
\text { ion }\end{array}$ & .06 & .33 & .03 & .38 & .67 \\
\hline & High & 6959 & 6965 & 6920 & 6923 & 6927 \\
\hline & voltag & .53 & .50 & .23 & .53 & .49 \\
\hline
\end{tabular}


Nur Haziqah Syazni Mohd Hatta et al., International Journal of Emerging Trends in Engineering Research, 8(1.1), 2020, $179-186$

\begin{tabular}{|c|c|c|c|c|c|c|}
\hline & $\begin{array}{l}\text { electr } \\
\text { ode }\end{array}$ & & & & & \\
\hline \multirow[t]{3}{*}{$\begin{array}{c}\text { Unsymme } \\
\text { trical }\end{array}$} & $\begin{array}{l}\text { Groun } \\
\text { d } \\
\text { Electr } \\
\text { ode }\end{array}$ & $\begin{array}{c}2158 \\
.04\end{array}$ & $\begin{array}{c}2189 \\
.55\end{array}$ & $\begin{array}{c}2114 \\
.89\end{array}$ & $\begin{array}{c}2160 \\
.86\end{array}$ & $\begin{array}{c}2149 \\
.02\end{array}$ \\
\hline & $\begin{array}{c}\text { Center } \\
\text { of } \\
\text { insulat } \\
\text { ion }\end{array}$ & $\begin{array}{l}4868 \\
.12\end{array}$ & $\begin{array}{c}4935 \\
.30\end{array}$ & $\begin{array}{l}4866 \\
.55\end{array}$ & $\begin{array}{c}4903 \\
.40\end{array}$ & $\begin{array}{c}4889 \\
.04\end{array}$ \\
\hline & $\begin{array}{l}\text { High } \\
\text { voltag } \\
\mathrm{e} \\
\text { electr } \\
\text { ode }\end{array}$ & $\begin{array}{c}6944 \\
.04\end{array}$ & $\begin{array}{c}6948 \\
.49\end{array}$ & $\begin{array}{c}6927 \\
.91\end{array}$ & $\begin{array}{c}6929 \\
.74\end{array}$ & $\begin{array}{c}6938 \\
.04\end{array}$ \\
\hline
\end{tabular}

Table 4: Electric field distribution of void in silicone rubber insulation [23]

\begin{tabular}{|c|c|c|c|c|c|c|}
\hline \multirow{2}{*}{$\begin{array}{l}\text { Shape of } \\
\text { cavity }\end{array}$} & \multirow{2}{*}{$\begin{array}{l}\text { Positi } \\
\text { on of } \\
\text { cavity }\end{array}$} & \multicolumn{5}{|c|}{ Electric field in channels (V) } \\
\hline & & 1 & 2 & 3 & 4 & 5 \\
\hline \multirow{6}{*}{$\begin{array}{c}\text { Cylindric } \\
\text { al }\end{array}$} & Groun & 2637 & 2639 & 2615 & 2635 & 2635 \\
\hline & $\begin{array}{c}\mathrm{d} \\
\text { Electr } \\
\text { ode }\end{array}$ & .13 & .78 & .07 & .15 & .52 \\
\hline & Center & 5254 & 5346 & 5277 & 5342 & 5295 \\
\hline & $\begin{array}{c}\text { of } \\
\text { insulat } \\
\text { ion }\end{array}$ & .06 & .36 & .25 & .77 & .45 \\
\hline & High & 6752 & 6756 & 6678 & 6714 & 6751 \\
\hline & $\begin{array}{c}\text { voltag } \\
\mathrm{e} \\
\text { electr } \\
\text { ode }\end{array}$ & .93 & .01 & .38 & .81 & .01 \\
\hline \multirow[t]{6}{*}{ Spherical } & Groun & 2867 & 3028 & 2788 & 2870 & 3017 \\
\hline & $\begin{array}{c}\mathrm{d} \\
\text { Electr } \\
\text { ode }\end{array}$ & .75 & .31 & .44 & .75 & .51 \\
\hline & Center & 4705 & 4706 & 4637 & 4641 & 4645 \\
\hline & $\begin{array}{c}\text { of } \\
\text { insulat } \\
\text { ion }\end{array}$ & .51 & .99 & .27 & .73 & .07 \\
\hline & High & 6560 & 6641 & 6313 & 6319 & 6326 \\
\hline & $\begin{array}{c}\text { voltag } \\
\text { e } \\
\text { electr } \\
\text { ode }\end{array}$ & .17 & .38 & .22 & .04 & .15 \\
\hline \multirow{6}{*}{$\begin{array}{c}\text { Unsymme } \\
\text { trical }\end{array}$} & Groun & 2133 & 2253 & 2052 & 2060 & 2133 \\
\hline & $\begin{array}{c}\mathrm{d} \\
\text { Electr } \\
\text { ode }\end{array}$ & .49 & .10 & .55 & .21 & .10 \\
\hline & Center & 4702 & 4722 & 4693 & 4710 & 4711 \\
\hline & $\begin{array}{c}\text { of } \\
\text { insulat } \\
\text { ion }\end{array}$ & .46 & .01 & .98 & .25 & .04 \\
\hline & High & 6493 & 6503 & 6387 & 6485 & 6488 \\
\hline & $\begin{array}{l}\text { voltag } \\
\mathrm{e} \\
\text { electr }\end{array}$ & .62 & .66 & .66 & .88 & .63 \\
\hline
\end{tabular}

\begin{tabular}{|c|c|c|c|c|c|c|}
\hline & ode & & & & & \\
\hline & Table 5: & $\begin{array}{r}\text { ectric f } \\
\text { carb }\end{array}$ & $\begin{array}{l}\text { Id distril } \\
\text { le insula }\end{array}$ & $\begin{array}{l}\text { ation o } \\
\text { on [23 }\end{array}$ & oid in & \\
\hline \multirow{2}{*}{$\begin{array}{c}\text { Shape of } \\
\text { cavity }\end{array}$} & \multirow{2}{*}{$\begin{array}{l}\text { Positi } \\
\text { on of } \\
\text { cavity }\end{array}$} & \multicolumn{5}{|c|}{ Electric field in channels $(\mathrm{V})$} \\
\hline & & $\mathbf{1}$ & 2 & 3 & 4 & 5 \\
\hline \multirow[t]{3}{*}{$\begin{array}{c}\text { Cylindric } \\
\text { al }\end{array}$} & $\begin{array}{c}\text { Groun } \\
\text { d } \\
\text { Electr } \\
\text { ode }\end{array}$ & 2639 & $\begin{array}{c}2642 \\
.55\end{array}$ & $\begin{array}{l}2576 \\
.05\end{array}$ & $\begin{array}{c}2590 \\
.70\end{array}$ & $\begin{array}{c}2639 \\
.95\end{array}$ \\
\hline & $\begin{array}{l}\text { Center } \\
\text { of } \\
\text { insulat } \\
\text { ion }\end{array}$ & $\begin{array}{c}5173 \\
.93\end{array}$ & $\begin{array}{c}5312 \\
.97\end{array}$ & $\begin{array}{c}5132 \\
.93\end{array}$ & $\begin{array}{c}5265 \\
.35\end{array}$ & $\begin{array}{c}5238 \\
.52\end{array}$ \\
\hline & $\begin{array}{c}\text { High } \\
\text { voltag } \\
\mathrm{e} \\
\text { electr } \\
\text { ode }\end{array}$ & $\begin{array}{l}6612 \\
.99\end{array}$ & $\begin{array}{c}6666 \\
.58\end{array}$ & $\begin{array}{c}6258 \\
.93\end{array}$ & $\begin{array}{c}6619 \\
.51\end{array}$ & $\begin{array}{c}6461 \\
.79\end{array}$ \\
\hline \multirow[t]{3}{*}{ Spherical } & $\begin{array}{c}\text { Groun } \\
\text { d } \\
\text { Electr } \\
\text { ode }\end{array}$ & $\begin{array}{c}3869 \\
.13\end{array}$ & $\begin{array}{c}3922 \\
.07\end{array}$ & $\begin{array}{c}3861 \\
.11\end{array}$ & $\begin{array}{c}3876 \\
.42\end{array}$ & $\begin{array}{c}3885 \\
.43\end{array}$ \\
\hline & $\begin{array}{l}\text { Center } \\
\text { of } \\
\text { insulat } \\
\text { ion }\end{array}$ & $\begin{array}{l}4845 \\
.22\end{array}$ & $\begin{array}{c}4896 \\
.08\end{array}$ & $\begin{array}{l}4842 \\
.43\end{array}$ & $\begin{array}{c}4843 \\
.15\end{array}$ & $\begin{array}{c}4843 \\
.95\end{array}$ \\
\hline & $\begin{array}{c}\text { High } \\
\text { voltag } \\
\text { e } \\
\text { electr } \\
\text { ode }\end{array}$ & $\begin{array}{c}6379 \\
.28\end{array}$ & $\begin{array}{c}6439 \\
.39\end{array}$ & $\begin{array}{c}6376 \\
.84\end{array}$ & $\begin{array}{c}6432 \\
.08\end{array}$ & $\begin{array}{c}6424 \\
.23\end{array}$ \\
\hline \multirow[t]{3}{*}{$\begin{array}{c}\text { Unsymme } \\
\text { trical }\end{array}$} & $\begin{array}{c}\text { Groun } \\
\text { d } \\
\text { Electr } \\
\text { ode }\end{array}$ & $\begin{array}{c}1945 \\
.31\end{array}$ & $\begin{array}{c}1957 \\
.97\end{array}$ & $\begin{array}{c}1845 \\
.82\end{array}$ & $\begin{array}{c}1955 \\
.32\end{array}$ & $\begin{array}{c}1924 \\
.36\end{array}$ \\
\hline & $\begin{array}{c}\text { Center } \\
\text { of } \\
\text { insulat } \\
\text { ion }\end{array}$ & $\begin{array}{l}4668 \\
.08\end{array}$ & $\begin{array}{c}4686 \\
.75\end{array}$ & $\begin{array}{c}4655 \\
.01\end{array}$ & 4661 & $\begin{array}{c}4680 \\
.28\end{array}$ \\
\hline & $\begin{array}{c}\text { High } \\
\text { voltag } \\
\mathrm{e} \\
\text { electr } \\
\text { ode }\end{array}$ & $\begin{array}{c}6375 \\
.54\end{array}$ & $\begin{array}{c}6434 \\
.21\end{array}$ & $\begin{array}{c}6372 \\
.83\end{array}$ & $\begin{array}{c}6432 \\
.09\end{array}$ & $\begin{array}{c}6428 \\
.04\end{array}$ \\
\hline
\end{tabular}

Based on observation from the table of electric field magnitude of void above, it shows the magnitude of electric field is high when the location of void is close to the high voltage electrode.

At the same time, the electric field of unsymmetrical void is lower compared to other shapes of void. This shows, insulation with unsymmetrical shape of void is exposed to high damage during partial discharge occurrence.

Other than that, the magnitude of electric field is higher for polycarbonate insulation, followed by silicone rubber and 
lowest for silicon carbide. Therefore, partial discharge activity is less affected on polycarbonate insulation compared to other type of insulation.

Furthermore, channel 2 are the highest electric field distribution within cavity occurs meanwhile, channel 3 is the lowest electric field for the three types of insulating material. Based on the observation of result, polycarbonate insulation is less affected by PD.

From [24], the tape shield cable result are compared four types of water tree; no water tree (as shown in Figure 8), $50 \%$ of water tree, $70 \%$ of water tree and $90 \%$ of water tree. Figure 7 shows the color scale of electric potential for tape shielded cables.

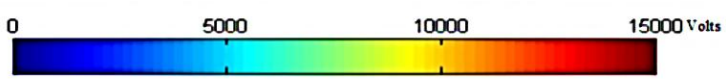

Figure 7: Color scale of electric potential of tape shielded cables [24]

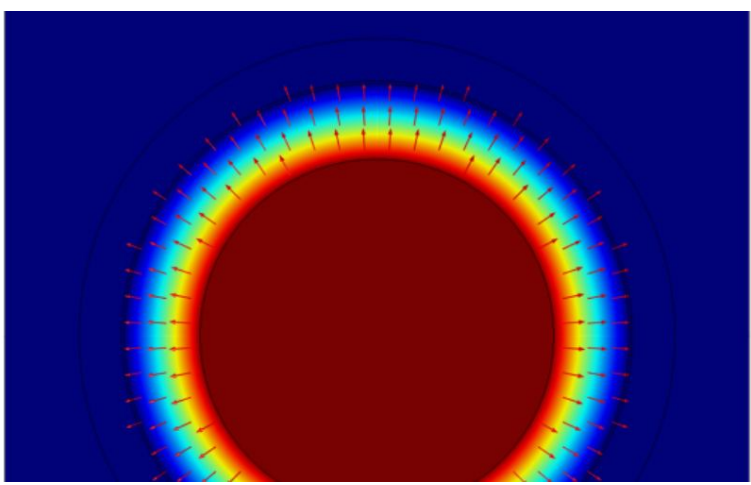

Figure 8: Tape shield cable with no water tree [24]

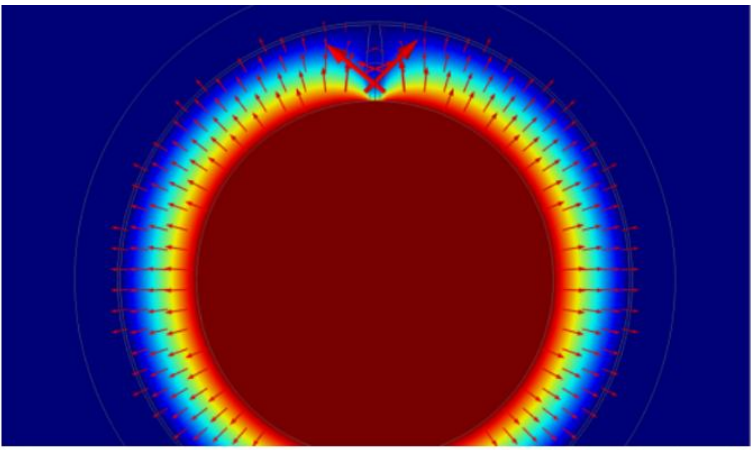

Figure 9: Tape shield cable with $100 \%$ of water tree [24]

From Figure 8 and Figure 9, it can be seen the difference of behavior of electric potential when water tree are presence across the insulation. The maximum potential is $15 \mathrm{kV}$ and reduces when reached the grounded tape shield which is nearly to zero volt for zero water tree. However, when the water tree is increasing to $100 \%$ of the insulation as in Figure 9, the electric field is touching the conductor. It will start to increase the electrons for electrical trees growth.
Meanwhile, for concentric neutral cable, the electric potential across the conductor and neutral wires is $10 \mathrm{kV}$. This can be seen through concentric neutral cable color scale of electric potential in Figure 10.

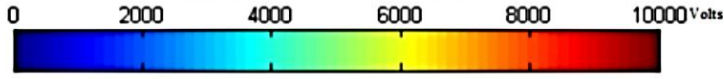

Figure 10: Color scale of concentric neutral cable electric potential [24]

The healthy concentric neutral cable are perpendicular to the conductor and act as Faraday cage to compare with area outside of the cable. It can be seen in a Figure 11.

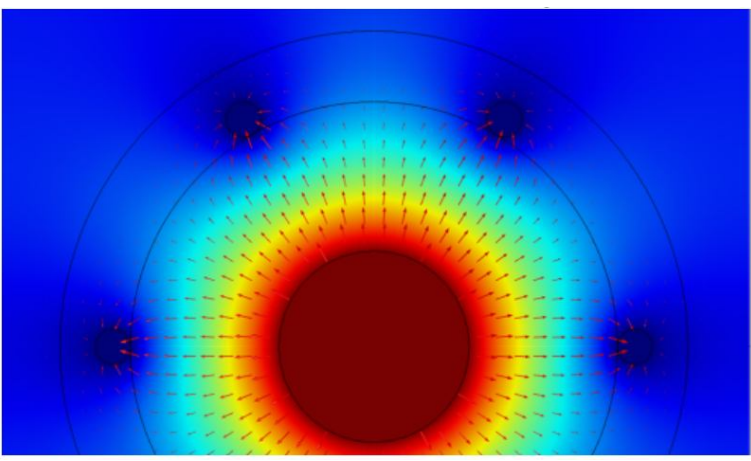

Figure 11: Concentric neutral cable with zero water tree [24]

Meanwhile, when the water tree is fully across the insulation of concentric neutral cable as seen in Figure 12, it will finally touching the conductor. This situation will allows huge amounts of electric field flowing between the surroundings of water tree and neutral wire.

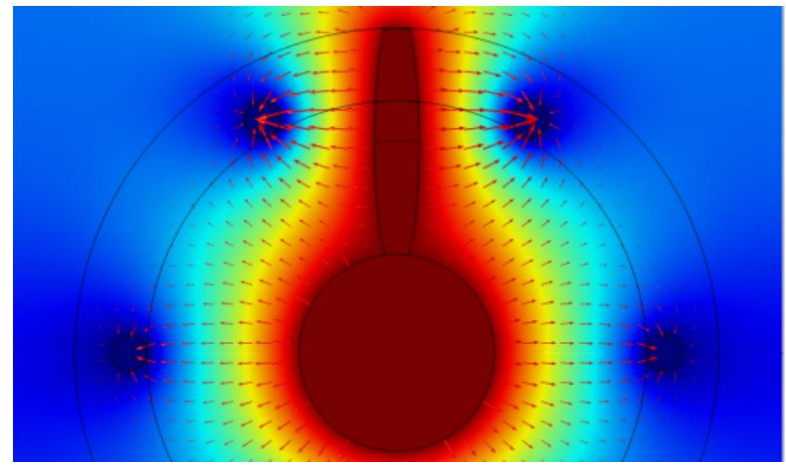

Figure 12: Concentric neutral cable with $100 \%$ water tree across the insulation [24]

Hence, by using COMSOL, the water tree presence can be shown inside the insulation for both type of cable. In addition, the proposed TDR method mentioned in [2], can determined the exact location of water tree on the cable. In addition, multiple water trees can be detected on the same cable. This method also can be installed on aged distribution feeders which does not require reference from previous monitoring methods. 
The signals collected will filter noise and performed the subtractions through a computer. It is verified using different case studies in real distribution system in periodic monitoring system not real-time monitoring system. TDR method also worked with optimal pulse generator placement and cable's measured signal created an inexpensive way in monitoring the critical distribution feeder health condition.

Based on the results of techniques demonstrated, finite element analysis of PD, water tree and TDR can be combined to achieve better performance of fault pinpointing. As stated earlier, by using TDR technique, water tree defects can be detected at the same time, can determine the location of the fault. Correspondingly to PD technique can detect the other type of fault happen in the insulation of the cable. The idea of combining the two methods comes with different advantages which will benefit the energy industry such as more types of fault can be detected, lesser the time required in finding fault on cable and reduce the cost and time consume.

\section{CONCLUSION}

From the experiment conducted, a combination of PD-TDR has been proposed. Result from the simulation and technique shown above makes the objectives of this study is achieved. The combination of PD-TDR technique will benefit the electrical energy field by providing the efficient technique to ensure the health of power cable can sustain to a very long time. This technique can provide the best solution in cable replacement during breakdown or routine maintenance based. Lesser time required to find the fault in the cable and at the same time, the type of defects also provided by the technique.

In future, further studies can be conducted to reinforce the finding of this technique combination. At the same time, this development is needed to increase the stability of electrical power supply to benefit the whole nation.

\section{ACKNOWLEDGEMENT}

The authors would like to thank Universiti Tenaga Nasional, Malaysia for funding this project under the BOLD Research Grant (RJO10517844/047).

\section{REFERENCES}

1. B. V. Wong, Y. Tian, and T. Neier. Practical experience using VLF Tan Delta and Partial Discharge measurement in medium voltage cable, in CMD 2016 - International Conference on Condition Monitoring and Diagnosis, 2016.

2. K. W. Burkes, E. B. Makram, and R. Hadidi. Water Tree Detection in Underground Cables Using Time Domain Reflectometry, IEEE Power Energy Technol. Syst. J., vol. 2, no. March, pp. 53-62, 2015.
3. E. A. Morris, W. H. Siew, and M. J. Given. Methods of Characterisation of DC Partial Discharge in Polymeric Cable Insulation, Annu. Rep. - Conf. Electr. Insul. Dielectr. Phenomena, CEIDP, vol. 2018-Octob, pp. 494-497, 2018.

4. R. Cselkó and I. Berta. Occurrence of partial discharges in low voltage cables due to artificial mechanical injuries, Proc. 2011 3rd Int. Youth Conf. Energ. IYCE 2011, pp. 1-6, 2011.

5. T. Ming, S. Jianyang, G. Jianzhao, L. Hongjie, Z. Wei, and L. Deliang. Time-domain modeling and simulation of partial discharge on medium-voltage cables by vector fitting method, IEEE Trans. Magn., vol. 50, no. 2, pp. 2-5, 2014.

6. H. Voltage. Very Low Frequency Ac Hipots a Review of Vlf Testing \& Answers, pp. 31-34.

7. H. A. Illias, M. A. Tunio, A. H. A. Bakar, H. Mokhlis, and G. Chen. Partial discharge phenomena within an artificial void in cable insulation geometry: Experimental validation and simulation, IEEE Trans. Dielectr. Electr. Insul., 2016.

8. B. Florkowska, J. Roehrich, P. Zydron, M. Florkowski, and A. Rybak. Interaction of conductor with polymeric materials (XLPE/EPR) at partial discharges, IEEE Trans. Dielectr. Electr. Insul., vol. 19, no. 6, pp. 2119-2127, 2012.

9. L. Niemeyer. A Generalized Approach to Partial Discharge Modeling, IEEE Trans. Dielectr. Electr. Insul., 1995.

10. L. Hao, P. L. Lewin, and S. J. Dodd. Partial discharge source characterization within a HV cable joint, 2007 Int. Conf. Solid Dielectr. ICSD, pp. 577-580, 2007.

11. L. Hao, P. L. Lewin, and S. J. Dodd. Partial discharge source characterization within a HV cable joint, in 2007 International Conference on Solid Dielectrics, ICSD, 2007.

12. Y. Tian, P. L. Lewin, A. E. Davies, S. G. Swingler, S. J. Sutton, and G. M. Hathaway. Comparison of on-line partial discharge detection methods for $\mathrm{HV}$ cable joints, IEEE Trans. Dielectr. Electr. Insul., 2002.

13. G. Robles, M. Shafiq, and J. M. Martínez-Tarifa. Multiple Partial Discharge Source Localization in Power Cables through Power Spectral Separation and Time-Domain Reflectometry, IEEE Trans. Instrum. Meas., vol. 68, no. 12, pp. 4703-4711, 2019.

14. S. B. Jones, J. M. Wraith, and D. Or. Time domain reflectometry measurement principles and applications, Hydrol. Process., vol. 16, no. 1, pp. 141153, 2002.

15. A. Cozza. Never trust a cable bearing echoes: Understanding ambiguities in time-domain reflectometry applied to soft faults in cables, IEEE Trans. Electromagn. Compat., vol. 61, no. 2, pp. 586589, 2019.

16. A. Laib, M. Melit, B. Nekhoul, K. El Khamlichi Drissi, and K. Kerroum. Soft fault identification in electrical network using time domain reflectometry and neural network, Lect. Notes Electr. Eng., vol. 522, pp. 365- 
376, 2019.

17. P. Mlynek, R. Fujdiak, and J. Misurec. Power line topology prediction using time domain reflectometry, 2016 39th Int. Conf. Telecommun. Signal Process. TSP 2016, pp. 199-202, 2016.

18. A. Vandana, R. Mohan, A. Abdul, B. Sujatha, and B. Nanda Kishore. Fault detection in three phase transmission line using wavelet transform algorithm, Int. J. Adv. Trends Comput. Sci. Eng., vol. 8, no. 1, pp. 82-84, 2019.

19. N. M. M. Farid et al.. Evolutionary symbiotic organisms search technique in power scheduling for loss control in power transmission system, Int. J. Adv. Trends Comput. Sci. Eng., vol. 8, no. 1.3 S1, pp. 431437, 2019.

20. A. R. A. Samsudin. Voltage Stability Assessment Using LVSI Under (N-m) Contingency, Int. J. $A d v$. Trends Comput. Sci. Eng., vol. 9, no. 1.2, pp. 1-5, 2020.

21. W. J. K. Raymond, H. A. Illias, A. H. A. Bakar, and H. Mokhlis. Partial discharge classifications: Review of recent progress, Measurement: Journal of the International Measurement Confederation. 2015.

22. A. N. Jahromi. Review of field acceptance hipot \& PD testing of medium voltage underground cables, in 2017 IEEE Electrical Insulation Conference, EIC 2017, 2017.

23. L. Seenivasagam, R. V. Maheswari, and P. Subburaj. Modelling of partial discharge behaviour in a cavity within the solid dielectrics, Proc. IEEE Int. Conf. Circuit, Power Comput. Technol. ICCPCT 2013, no. I, pp. 618-624, 2013.

24. K. Burkes, E. Makram, and R. Hadidi. Modeling the Effect of a Water Tree inside Tape Shield and Concentric Neutral Cables, 2014.

25. S. Conti, E. Dilettoso, and S. A. Rizzo. Electromagnetic and thermal analysis of high voltage three-phase underground cables using finite element method, Proc. - 2018 IEEE Int. Conf. Environ. Electr. Eng. 2018 IEEE Ind. Commer. Power Syst. Eur. EEEIC/I CPS Eur. 2018, vol. 2018, 2018.

26. N. N. Binti Abdul Rahim and N. A. Binti Muhamad. Application of COMSOL multiphysics in finding temperature distribution pattern in EPR cable with presence of void, IEEE Reg. 10 Annu. Int. Conf. Proceedings/TENCON, vol. 2017-Decem, pp. 82-87, 2017. 